\title{
Study of internal corrosion on the turning angles in steel pipes
}

\author{
Bauyrzhan Manapbayev ${ }^{1, *}$, Bazartai Alimbayev ${ }^{1}$,Erkegali Amanbayev ${ }^{1}$, Arman Kabdushev ${ }^{1}$, and Zhangazy \\ Moldamuratov $^{1}$ \\ ${ }^{1}$ M.Kh. Dulaty Taraz State University, Taraz, Kazakhstan
}

\begin{abstract}
Corrosive damages can lead to accidents on pipelines in various industries. Therefore, the main objective of the work is to study the peculiarities of propagation of internal corrosion on turning angles in steel pipes. The paper substantiates the primary importance of the propagation of corrosion on turning angles in steel pipes. It has been identified that in curvilinear areas, the rate of corrosion propagation depends on the rate of fluid flow, on the number of ions, and also on the effect of centrifugal force. The authors studied the average rate of corrosion propagation on the turns in steel pipes. Thus, the results obtained showed that the location of steel pipes affect the rate of corrosion propagation inside the pipes.
\end{abstract}

\section{Introduction}

Pipelines are located in different conditions depending on the terrain and depending on their activities. They are divided into several parts: straight, curved and vertical $90^{\circ}$ turns. Our experimental studies [1] on the propagation of corrosion have shown that the propagation of corrosion occurs more intensively on turning angles of steel pipes than on straight sections. With this regard, we conduct research on the mechanisms of corrosion propagation that occur on the inner walls of straight and curved parts of steel pipes.

Works related to the study of the features of corrosion occurring on the internal walls of curved (bends and turns) pipeline sections are not large. In some works in this direction [2-6] it was noted that the liquid moving along the inner surface of pipelines affects the propagation of internal corrosion when turning them at different angles. However, the work in this direction has not yet been studied at the proper level.

\section{Methodology}

For experimental studies, a device has been developed to determine the propagation of metal corrosion under the influence of a $3.5 \% \mathrm{NaCl}$ solution [7] from steel pipes. This installation consists of a pump, pipes welded at various angles with a diameter of $\varnothing 32 \times 3$, filters, air valves and supports (Fig.1). In our installation there are sections of straight (first section), curved (second section) and steel pipes that are diverted to $90^{\circ}$ (third section) (Fig.2) rotating with a liquid pump.

In the center of the upper part of the unit, a pump that pumps $3.5 \% \mathrm{NaCl}$ solution into the system is installed. The pump is connected to a time relay, works for 1 hour continuously, and is idle for 20 minutes. The wall thickness of steel pipes is measured by an ultrasonic thickness gauge. Due to various methods, the ultrasonic method gives good results [8]. The pipe material is steel grade 10 with a diameter of $\varnothing 32 \times 3,0$. Measurements were made 3 times a year. The results of these studies have shown special facts, especially in sections of steel pipes that are diverted at $90^{\circ}$. Their results can be seen in tables $1,2,3$.

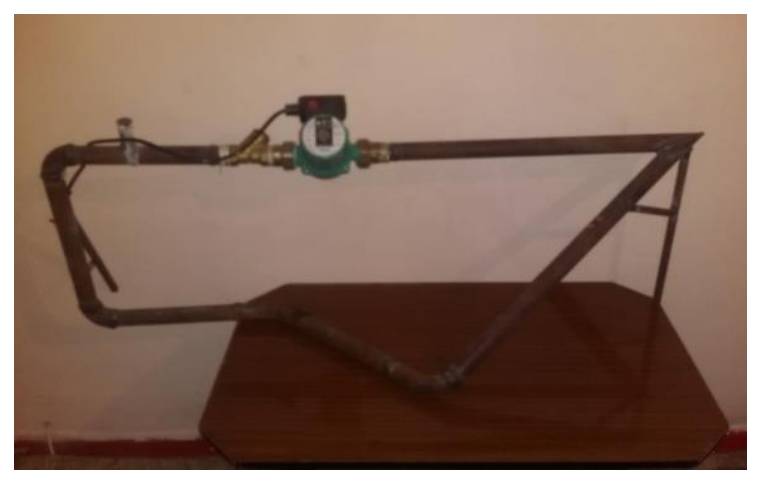

Fig.1. Installation for investigation of corrosion in internal compartments of steel pipes.

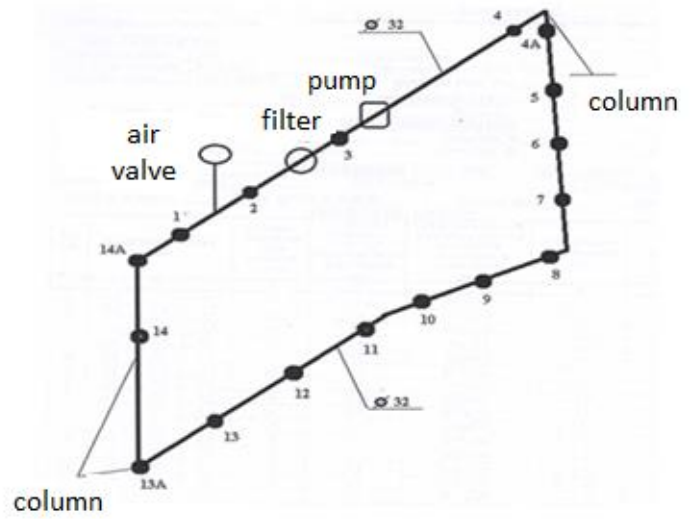

Fig.2. Location of measuring points on the installation.

\footnotetext{
"Corresponding author: jiboj@mail.ru
} 
Table 1. Results of pipe thickness measurements in straight sections.

\begin{tabular}{|c|c|}
\hline $\begin{array}{c}\text { Number of measured } \\
\text { points }\end{array}$ & $\begin{array}{l}\text { Measured wall thickness } \\
(\mathbf{m m})\end{array}$ \\
\hline \multicolumn{2}{|c|}{ after 3 months } \\
\hline 1 & 2,9 \\
\hline 2 & 3,0 \\
\hline 3 & 2,9 \\
\hline 4 & 2,9 \\
\hline 7 & 3,0 \\
\hline 12 & 3,0 \\
\hline 14 & 2,8 \\
\hline \multicolumn{2}{|c|}{ after 8 months } \\
\hline 1 & 2,9 \\
\hline 2 & 2,9 \\
\hline 3 & 2,8 \\
\hline 4 & 2,8 \\
\hline 7 & 2,9 \\
\hline 12 & 2,9 \\
\hline 14 & 2,8 \\
\hline \multicolumn{2}{|c|}{ after 12 months } \\
\hline 1 & 2,8 \\
\hline 2 & 2,8 \\
\hline 3 & 2,8 \\
\hline 4 & 2,8 \\
\hline 7 & 2,8 \\
\hline 12 & 2,8 \\
\hline 14 & 2,8 \\
\hline
\end{tabular}

Table 2. Results of pipe thickness measurements on turning angles.

\begin{tabular}{|c|c|}
\hline $\begin{array}{c}\text { Number of measured } \\
\text { points }\end{array}$ & $\begin{array}{c}\text { Measured wall thickness } \\
\text { (mm) }\end{array}$ \\
\hline \multicolumn{2}{|c|}{ after 3 months } \\
\hline 5 & 2,8 \\
\hline 6 & 2,9 \\
\hline 9 & 2,6 \\
\hline 10 & 2,9 \\
\hline 11 & 2,9 \\
\hline 13 & 2,6 \\
\hline \multicolumn{2}{|c|}{ after 8 months } \\
\hline 5 & 2,7 \\
\hline 6 & 2,8 \\
\hline 9 & 2,6 \\
\hline 10 & 2,7 \\
\hline 11 & 2,9 \\
\hline 13 & 2,6 \\
\hline & after 12 months \\
\hline 5 & 2,6 \\
\hline 6 & 2,6 \\
\hline 9 & 2,6 \\
\hline 10 & 2,6 \\
\hline 11 & \\
\hline 13 & \\
\hline
\end{tabular}

Table 3. Results of measurements of the pipeline thickness in the sections diverted by $90^{\circ}$.

\begin{tabular}{|c|c|}
\hline $\begin{array}{c}\text { Number of measured } \\
\text { points }\end{array}$ & $\begin{array}{c}\text { Measured wall thickness } \\
\text { (mm) }\end{array}$ \\
\hline \multicolumn{2}{|c|}{ after 3 months } \\
\hline $4 \mathrm{~A}$ & 2,8 \\
\hline 8 & 2,6 \\
\hline $13 \mathrm{~A}$ & 2,6 \\
\hline $14 \mathrm{~A}$ & 2,8 \\
\hline \multicolumn{2}{|c|}{ after 8 months } \\
\hline $8 \mathrm{~A}$ & 2,1 \\
\hline $13 \mathrm{~A}$ & 2,3 \\
\hline $14 \mathrm{~A}$ & 2,4 \\
\hline \multicolumn{2}{|c|}{ after 12 months } \\
\hline 8 & 2,2 \\
\hline $13 \mathrm{~A}$ & 2,0 \\
\hline $14 \mathrm{~A}$ & 2,2 \\
\hline
\end{tabular}

\section{Results and discussion}

The average rate of corrosion propagation in steel pipes with a straight section was equal to $0.2 \mathrm{~mm} /$ year. On straight sections of steel pipes, corrosion first actively develops, then the rate of corrosion propagation slows down. After that, after a certain time, the corrosion develops again. After the first measurement, the microchips of the inner surface of the pipeline produce chemical reaction products-micelles (chemical product of corrosion), filling their cracks and reducing the speed of the corrosion process.

The average rate of corrosion propagation on turning angles of steel pipes (bends and turns) was equal to $0.375 \mathrm{~mm} /$ year. Compared with a straight section of steel pipes, the value obtained on turning angles (bends and turns) has increased significantly. This phenomenon is explained by the fact that when turning steel pipes, the liquid under the influence of centrifugal forces hit the walls and washed the micelles, so the physical process is not stopped by the influence of the rate of corrosion propagation.

The average rate of corrosion propagation at turns of steel pipes, equal to $90^{\circ}$, is equal to $0.833 \mathrm{~mm} /$ year. Compared with a straight section of steel pipes, the resulting value at turns, equal to $90^{\circ}$, significantly increased (Fig. 3). This phenomenon is explained by the fact that the liquid completely breaks its structure when turning $90^{\circ}$ and the number of ions in the $\mathrm{NaCl}$ solution increases along the perimeter of the cylinder in proportion to the ratio of the volume of the cylinder.

\footnotetext{
*Corresponding author: jiboj@mail.ru
} 


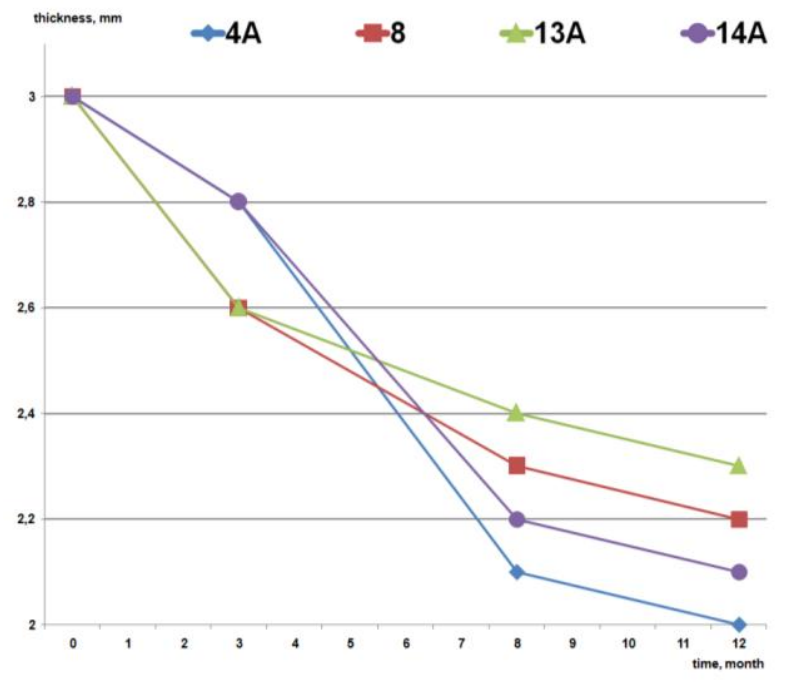

Fig.3. Graphs of the pipeline thickness depletion from corrosion depending on the time on the sections diverted to $90^{\circ}$.

This experiment showed that the location of steel pipes in the plane (straight sections, bends and turns) affects the rate of corrosion propagation inside the pipes. In comparison, the corrosion of curved pipes is 1.875 times greater than that of straight pipes. And on sections of vertical $90^{\circ}$ swivel pipes, the corrosion is 4.165 times greater than in the straight part. At the same time, it can be assumed that the flow of liquid and the forces generated on parts of curved and vertically rotating pipelines, respectively, an increase in the number of ions in the $\mathrm{NaCl}$ solution in them significantly affects the rate of corrosion propagation.

Therefore, the number of ions in the $\mathrm{NaCl}$ solution that affect the rate of corrosion propagation inside the pipeline is characterized as follows. The number of ions in the straight part of the pipeline is equal to

$$
\boldsymbol{\pi} \cdot \boldsymbol{d} \cdot N_{1}
$$

where $N_{1}$ is the number of ions located on a cylindrical surface, from their influence corrosion occurs at a rate of $\omega_{1}$. When the pipe is rotated $90^{\circ}$ the number of ions is equal to

$$
\frac{\boldsymbol{\pi} \cdot d^{2}}{4} \cdot N_{2}
$$

where $N_{2}$ is the number of ions located in the volume of the cylinder, from their influence, corrosion occurs at a rate of $\omega_{2}$. Thus, when the pipe is rotated $90^{\circ}$, the number of ions in the liquid increases by

$$
\frac{N_{2} \cdot d^{2}}{4 \cdot N_{1}}
$$

The following conclusions can be drawn from the above:

1. The number of ions in a straight pipe directly depends on the surface of the cylinder.

2. When the pipe is rotated $90^{\circ}$ the number of ions depends on the cross-section of the cylinder. At the same time, if the speed of solution flow changes dramatically, the number of ions increases and affects the centrifugal thrust. Accordingly, corrosion on the inner wall of the pipe develops quickly.

\section{Conclusion}

The results of the research have shown that pipelines can lose their functionality as a result of corrosion. We have found that pipes with u-turn angles, especially pipelines, can lose their trouble-free operation when turning $90^{\circ}$ because of corrosion in comparison to sections of pipelines with straight sections. This issue is very relevant in industrial oil and gas pipelines, as it is known that internal corrosion develops intensively in the places of welding, broken structures, and turns that are local barriers. At the same time, this issue is not being studied at the proper scientific level.

As a rule, building codes do not allow for the propagation of corrosion in the calculation formulas of steel pipes, but the propagation of corrosion is taken into account by the coefficient of working conditions. This coefficient does not take into account the impact of corrosion propagation in tubular steel structures in areas with bends. Experimental studies of the propagation of corrosion in tubular steel structures have shown that corrosion develops much faster than straight sections when turning pipes by $90^{\circ}$. Failure to take this phenomenon into account may lead to premature failure of rotary steel structures. To eliminate this phenomenon, it is necessary to take measures that ensure equal reliability of all sections of tubular steel structures, thus ensuring their smooth operation.

\section{References}

1. Amanbayev E., Alimbayev B., Manapbayev B., Djanuzakova R., Internal propagation behavior on the turning angles in steel pipes (Manufacturing Technology, 19, 359-365, 2019)

2. Zhang H., Lan H., Lin N., A numerical simulation of water distribution associated with internal corrosion induced by water wetting in upward inclined oil pipes (Journal of Petroleum Science and Engineering, 173, 351-361, 2019)

3. Pouraria H., Seo J.K., Paik J.K., A numerical study on water wetting associated with the internal corrosion of oil pipelines (Ocean Engineering, 122, 105-117, 2016)

4. Henthorne M., The Slow Strain Rate Stress Corrosion Cracking Test-A 50 Year Retrospective (Corrosion, 72, 1488-1518, 2016)

5. Papavinasam S., Doiron A., Revie R.W., Model to Predict Internal Pitting Corrosion of Oil and Gas Pipelines (Corrosion, 66, 035006-035006-11, 2010)

6. Liang Fan, Fujian Tang, Signo T. Reis, Genda Chen, Michael L. Koenigstein, Corrosion Resistances of

\footnotetext{
*Corresponding author: jiboj@mail.ru
} 
Steel Pipes Internally Coated with Enamel (Corrosion, 73, 1335-1345, 2017)

7. Revie R.W. (Ed), Uhlig's corrosion handbook. 3rd ed (Hoboken, New Jersey, 2011)

8. Fedotov S.D., Ulybin A.V., Shabrov N.N., The methodology of determining the corrosion of steel structures (Magazine of Civil Engineering, 36(1), 12-20, 2013)

* Corresponding author: jiboj@mail.ru 